Fifth International Conference on Sustainable Construction Materials and Technologies. http://www.claisse.info/Proceedings.htm

\title{
NANO-MODIFIED CEMENTITIOUS COMPOSITES WITH HIGH VOLUME SUPPLEMENTARY CEMENTITIOUS MATERIALS INCORPORATING BASALT FIBER PELLETS
}

\author{
A.Azzam ${ }^{1}$, M.T. Bassuoni2 ${ }^{*}$, and A. Shalaby ${ }^{3}$ \\ ${ }^{1} \mathrm{PhD}$. Candidate, Civil Engineering, University of Manitoba, Winnipeg, Canada. \\ ${ }^{2 *}$ Associate Professor, Civil Engineering, University of Manitoba, Winnipeg, Canada (Corresponding \\ Author). \\ ${ }^{3}$ Professor, Civil Engineering, University of Manitoba, Winnipeg, Canada.
}

\begin{abstract}
In this study, high performance nano-modified cementitious composites were developed. These composites incorporate $50 \%$ fly ash or slag (industrial by-products) replacement of the cement component, 6\% nano-silica sol and a new type of basalt fiber strands encapsulated by polymeric resins termed as basalt fiber pellets. The fresh and mechanical properties were investigated for the developed composites with different dosages of basalt pellets $(2.5 \%, 4.5 \%$ and $6.9 \%$ by volume). Generally, the slag based composites showed improved performance compared to the fly ash based composites. Although the compressive strength of the specimens was reduced with increasing the dosage of pellets, the flexural performance of the composites was significantly enhanced in terms of post-cracking behavior, residual strength and toughness. Composites comprising $4.5 \%$ and $6.9 \%$ pellets exhibited deflectionhardening behavior. Hence, they have a promising potential for many infrastructure applications.
\end{abstract}

Keywords: Basalt Fiber Pellets, Nano-modified Cementitious Composites, PostCracking Behavior, Sustainability.

\section{INTRODUCTION}

One of the most sustainable approaches to reduce the carbon footprint and improve the performance of concrete is to use binder systems comprising supplementary cementitious materials (SCMs), such as fly ash and slag, as a partial replacement of cement (Cheah, 2014). The service life of concrete infrastructure (e.g. pavements, bridge decks, runways, etc.) depends on multiple factors including the rheological, mechanical as well as durability characteristics of the used materials, in addition to exposure conditions and loading configurations. Such interrelated parameters may stimulate initiation and propagation of cracks in concrete, which directly affect its overall performance and longevity, especially in locations susceptible to deteriorations such as joints in pavements and bridges (Jones et al., 2013). 
Fibers are typically added to enhance the ductility of cement-based materials. For instance, different types of fibers have been used to develop fiber-reinforced cementitious composites (FRCC) with improved flexural performance in terms of post-cracking behavior and toughness (Bentur and Mindess, 2014; Balaguru and Shah, 1992). Numerous studies have been carried out in this area to promote the use of FRCC (e.g. Li, 2003; Li et al., 2010; Lepech and Li, 2010; Zhu, 2013). More recently, FRCC has been developed using high performance cementitious matrices incorporating nanosilica particles (Ghazy et al. 2016a, Mahmoud et al. 2017) for various infrastructure applications.

Basalt fibers are considered a relatively new type of fibers, with high potential in the concrete industry owing to its good mechanical characteristics, non-corrosive nature, and low cost, relative to other kinds of fibers (e.g. steel, glass). In addition, basalt fibers production processes do not result in environmental waste; besides, they are nontoxic and biodegradable. However, basalt fibers were reported to have low resistance to alkaline media that made them vulnerable to degradation when incorporated in cement-based matrices, characterized by high $\mathrm{pH}$ of 12-13 (Lee et al., 2014). To mitigate this technical limitation, basalt fibers can be encapsulated with a polymeric resin (e.g. epoxy, polyamide, etc.) forming basalt fiber pellets (BFP).

The primary objective of this study was to develop nano-modified cementitious composites containing a high volume $(50 \%)$ of fly ash or slag in combination with different dosages of BFP. Six composites were designed at a constant water-to-binder ratio $(w / b)$ of 0.3 and binder content of $700 \mathrm{~kg} / \mathrm{m}^{3}$. The fresh properties, compressive strength and flexural strength as well as toughness of these composites were determined to evaluate their performance and suitability for structural applications.

\section{EXPERIMENTAL PROGRAM}

\section{Materials}

General use cement (GU), slag and fly ash, meeting CSA-A3001 (2013) requirements were used as the main components of the matrix (Table 1).

Table 1- Chemical and physical properties of GU cement, fly ash and slag

\begin{tabular}{lccc}
\hline Oxide Analysis/Physical Property & GU Cement & Fly ash & Slag \\
\hline $\mathrm{SiO}_{2}(\%)$ & 19.22 & 55.20 & 33.40 \\
$\mathrm{Al}_{2} \mathrm{O}_{3}(\%)$ & 5.01 & 23.13 & 13.40 \\
$\mathrm{Fe}_{2} \mathrm{O}_{3}(\%)$ & 2.33 & 3.62 & 0.76 \\
$\mathrm{CaO}(\%)$ & 63.22 & 10.81 & 42.70 \\
$\mathrm{MgO}(\%)$ & 3.31 & 1.11 & 5.30 \\
$\mathrm{SO}_{3}(\%)$ & 3.01 & 0.22 & 2.40 \\
$\mathrm{Na}_{2}$ Oeq. (\%) & 0.12 & 3.21 & 0.30 \\
Specific Gravity & 3.15 & 2.12 & 2.87 \\
Fineness , m$/ \mathrm{kg}$ & 390 & 290 & 492 \\
\hline
\end{tabular}


In addition, a commercial nano-silica sol (NS) was used in the matrix; this solution comprises $50 \% \mathrm{SiO}_{2}$ particles dispersed in an aqueous solution. The mean particle size of NS is $35 \mathrm{~nm}$, and its specific surface, viscosity, density, and $\mathrm{pH}$ values are $80 \mathrm{~m}^{2} / \mathrm{g}$, $8 \mathrm{cP}, 1.1 \mathrm{~g} / \mathrm{cm}^{3}$, and 9.5 , respectively. Locally available fine aggregate, with a continuous gradation of 0 to $600 \mu \mathrm{m}$ and fineness modulus of 2.9 was adopted in the mixtures. The absorption and specific gravity of the fine aggregate is $1.5 \%$ and 2.6 , respectively. A high-range water-reducing admixture (HRWRA), poly-carboxylic acid based complying with ASTM C494 Type F (2013), was added to achieve a target flow of $200 \pm 20 \mathrm{~mm}$ for all the mixtures. BFP of $36 \mathrm{~mm}$ length (Figure 1 and Table 2) were used to reinforce the cementitious composites at different dosages of $2.5 \%, 4.5 \%$ and $6.9 \%$ by volume (equivalent to basalt fibers volumes of $1 \%, 2 \%$ and $3 \%$, respectively). The BFP are made of $16 \mu \mathrm{m}$ basalt roving encapsulated by polyamide resin, and the fiber component represents $60 \%$ of the pellet by mass.

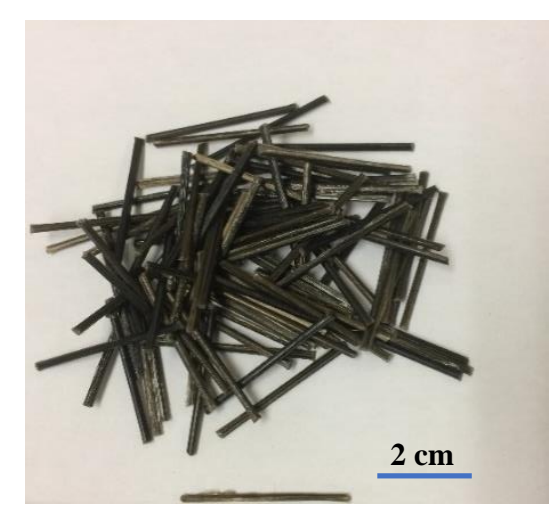

Figure 1-Reinforcing basalt fiber pellets.

Table 2- Physical and mechanical properties of basalt fiber pellets

\begin{tabular}{lc}
\hline Property & BFP \\
\hline Length $(\mathrm{mm})$ & 36 \\
Diameter/dimensions $(\mathrm{mm})$ & 1.8 \\
Aspect ratio & 20 \\
Specific gravity & 1.74 \\
Tensile strength $(\mathrm{MPa})$ & 2,300 \\
Elastic modulus $(\mathrm{GPa})$ & 65 \\
\hline
\end{tabular}

\section{Proportions and Mixing Procedures}

Six mixtures were prepared with three dosages of BFP and two different cementitious matrices. The base binders were composed of $50 \%$ GU cement and $50 \%$ fly ash or slag. Nano-silica was added at a single dosage of $6 \%\left(42 \mathrm{~kg} / \mathrm{m}^{3} \mathrm{SiO}_{2}\right)$ by mass of the base binder $\left(700 \mathrm{~kg} / \mathrm{m}^{3}\right)$, as this dosage was reported to positively influence the hardened properties of concrete (Said et al., 2012, Ghazy et al. 2016b). For all mixtures, the total cementitious materials (ternary binder of GU cement, slag/fly ash, and nano-silica) content and $w / b$ were kept constant at $742 \mathrm{~kg} / \mathrm{m}^{3}$ and 0.3 , respectively. The proportions of all the cementitious composites are presented in Table $\mathbf{3}$, and the 
mixtures were reinforced with $1 \%, 2 \%$ and $3 \%$ basalt fibers by volume, i.e. $2.5 \%, 4.5 \%$ and $6.9 \%$ BFP.

Table 3- Mixtures proportions per cubic meter

\begin{tabular}{ccccccccc}
\hline $\begin{array}{c}\text { Mixtur } \\
\text { e ID. }\end{array}$ & $\begin{array}{c}\text { Cement } \\
(\mathrm{kg})\end{array}$ & $\begin{array}{c}\text { Fly } \\
\text { ash } \\
(\mathrm{kg})\end{array}$ & $\begin{array}{c}\text { Slag } \\
(\mathrm{kg})\end{array}$ & $\begin{array}{c}\text { Water }^{*} \\
(\mathrm{~kg})\end{array}$ & $\begin{array}{c}\text { Nano- } \\
\text { silica } \\
(\mathrm{kg})\end{array}$ & $\begin{array}{c}\text { BFP } \\
(\mathrm{kg})\end{array}$ & $\begin{array}{c}\text { Fine } \\
\text { aggregate } \\
(\mathrm{kg})\end{array}$ & $\begin{array}{c}\text { HRWR } \\
(\mathrm{l})\end{array}$ \\
\hline F-2.5 & 350 & 350 & --- & 180 & 84 & 43.3 & 1,045 & 5.6 \\
F-4.5 & 350 & 350 & --- & 180 & 84 & 78.3 & 1,000 & 6.3 \\
F-6.9 & 350 & 350 & --- & 180 & 84 & 119.2 & 940 & 7.3 \\
G-2.5 & 350 & --- & 350 & 180 & 84 & 43.3 & 1,160 & 7.6 \\
G-4.5 & 350 & --- & 350 & 180 & 84 & 78.3 & 1,115 & 8 \\
G-6.9 & 350 & --- & 350 & 180 & 84 & 119.2 & 1,050 & 8.3 \\
\hline
\end{tabular}

*Adjusted amount of mixing water considering the water content of nano-silica (aqueous solution with $50 \%$ solid content of $\mathrm{SiO}_{2}$ ).

The constituent materials were mixed in a concrete mixer with a speed of $60 \mathrm{rpm}$. The mixing process comprised mixing the dry constituents followed by the addition of required water, admixtures and nano-silica while constantly mixing until the homogeneity of the mixture was achieved. Subsequently, the BFP were added and the ingredients were mixed for uniform distribution of pellets. The complete mixing process took about $10 \mathrm{~min}$. For the mixtures ID., the letter "G" refers to slag replacement, whereas the letter " $F$ " refers to fly ash replacement. The second part represents the BFP dosage as a percentage by volume.

\section{Tests}

In order to investigate the fresh properties of the developed mixtures, the mortar flow test was performed according to ASTM C230/C230M (2014). In addition, the setting times of the base mixtures were determined in accordance with ASTM C403 (2016), where fresh mortar without fibers was placed in a container at room temperature, and the penetration resistance was determined via standard needles at regular time intervals.

The hardened properties of the composites were assessed by determining the compressive strength and flexural behavior. The compressive strength of the mixtures was determined by testing triplicate cylinders $(100 \times 200 \mathrm{~mm})$ at two different ages $(3$ and 28 days) according to ASTM C39 (2018). The flexural strength as and postcracking behavior of the mixtures at 28 days was determined according to ASTM C1609 (2012), by testing triplicate prisms $(100 \times 100 \times 350 \mathrm{~mm})$ in four-point bending, as shown in Figure 2. A servo-controlled closed-loop testing machine was used, where the displacement rate relied on the measured net mid-span deflection of the prism. The flexural toughness was calculated as the area under the load-deflection curve $(P-\delta)$ up to a deflection of span/150 (2 mm). 


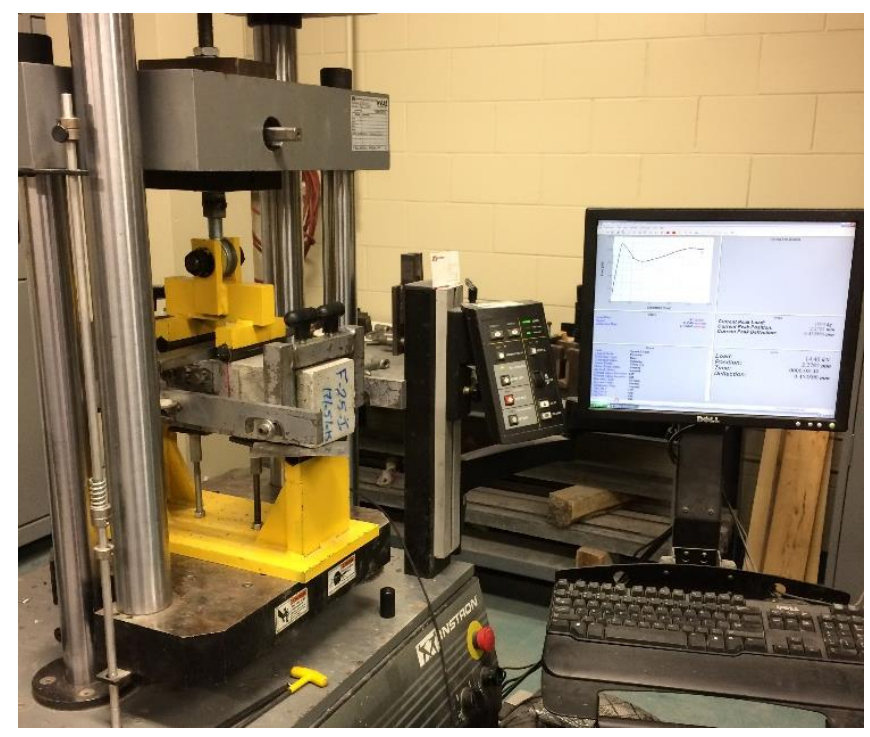

Figure 2-Flexural test setup.

\section{RESULTS AND DISCUSSION}

\section{Fresh Properties}

All the mixtures achieved the target flow of $200 \pm 20 \mathrm{~mm}(100 \pm 20 \%$ of the original base diameter of the mold). The slag-based mixtures required higher dosages of the HRWR to attain the target flow compared to the fly ash based mixtures, and the dosages were adjusted according to the content of the BF pellets (Table 3). This can be attributed to the angular shape of slag particles (interlocking effect) versus the spherical shape of fly ash particles, which imparted a ball bearing effect, thus enhancing the workability of the mortar mixtures (Neville, 2011).

The fly ash based mortar had 39\% and 26\% longer initial and final setting times, respectively relative to the slag-based mortar (Figure 3). This can be attributed to the retarding effect and slower reactivity of Type F fly ash, which is well-documented in the technical literature (Neville, 2011; Mehta and Monteiro, 2014), relative to the finer $\left(492 \mathrm{~kg} / \mathrm{m}^{3}\right)$ and relatively reactive (Grade 100) slag. Binders containing such high volumes of SCMs typically exhibit final settings times in the range of 9 to $12 \mathrm{~h}$ (Ramezanianpour, 2013; Ondova et al., 2013). However, the final setting times of both binders herein remained within the normal range of 4 to $6 \mathrm{~h}$, despite of the high volume $(50 \%)$ of fly ash and slag incorporated in these binders. This can be attributed to the ultrafine nature of silica particles $\left(80,000 \mathrm{~m}^{2} / \mathrm{kg}\right)$, resulting in accelerated rates of hardening and early hydration and pozzolanic reactivity. These trends agree with findings of previous studies (Zhang et al. 2012; Ghazy et al. 2016b) and indicate that the mixture design of the nano-modified cementitious composites herein can be used for most construction applications as it has an acceptable range of setting time. 


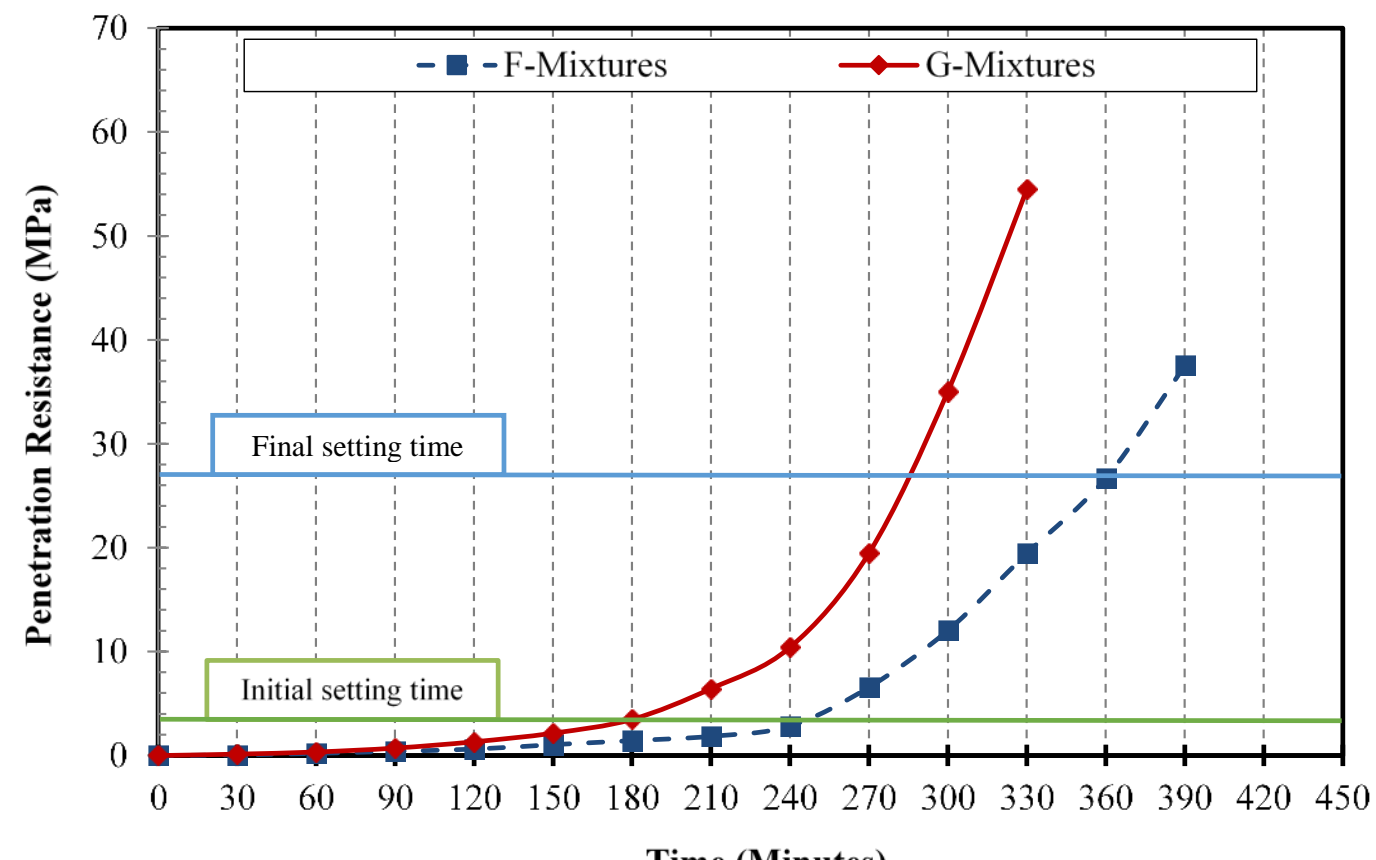

Time (Minutes)

Figure 3-Penetration resistance versus time.

\section{Compressive Strength}

Table 4 presents the average compressive strength for the developed composites at different ages (3 and 28 days).

Table 4-Compressive and flexural test results of the composites

\section{Compressive}

Strength (MPa)

\begin{tabular}{|c|c|c|c|c|c|c|}
\hline \multirow{2}{*}{$\begin{array}{l}\text { Mixtur } \\
\text { e ID }\end{array}$} & \multicolumn{2}{|c|}{ Age (Days) } & \multicolumn{4}{|c|}{ Flexural test results at 28 days } \\
\hline & 3 & 28 & $\begin{array}{c}\text { First- } \\
\text { peak } \\
\text { strength } \\
(\mathrm{MPa}) \\
\end{array}$ & $\begin{array}{c}\text { Residual } \\
\text { strength } \\
\text { at L/600 } \\
(\mathrm{MPa}) \\
\end{array}$ & $\begin{array}{c}\text { Residual } \\
\text { strength } \\
\text { at } \mathrm{L} / 150 \\
(\mathrm{MPa}) \\
\end{array}$ & $\begin{array}{c}\text { Toughness } \\
(\mathbf{J})\end{array}$ \\
\hline F-2.5 & $\begin{array}{c}36 . \\
9\end{array}$ & 53.8 & 5.3 & 4.2 & 4.0 & 27.4 \\
\hline F-4.5 & $\begin{array}{c}34 . \\
7\end{array}$ & 47.8 & 4.8 & 5.9 & 5.9 & 37.4 \\
\hline F-6.9 & $\begin{array}{c}34 . \\
1\end{array}$ & 46.3 & 4.6 & 5.9 & 6.3 & 39.9 \\
\hline G-2.5 & $\begin{array}{c}63 . \\
2\end{array}$ & 78.5 & 7.3 & 4.2 & 4.5 & 30.3 \\
\hline G-4.5 & $\begin{array}{c}58 . \\
9\end{array}$ & 69.7 & 5.1 & 4.8 & 5.1 & 40.3 \\
\hline G-6.9 & 53. & 57.6 & 4.8 & 6.0 & 5.9 & 44.0 \\
\hline
\end{tabular}


Cementitious binders comprising Type F fly ash (slow reactivity pozzolan) and slag (latent hydraulic binder) blended with GU cement typically exhibit slow rate of strength and microstructural development at early-age, but their reactivity improves with age (Mehta and Monteiro, 2014). However, the results herein indicate that the compressive strengths of all mixtures, comprising 50\% fly ash or slag, were greater than $30 \mathrm{MPa}$ at early-age. Conforming to the setting time results, the technical limitations (slow rate of reactivity and strength development) of binders incorporating a high volume of SCMs was mitigated by the nano-silica sol. Addition of $6 \%$ nanosilica increased the compressive strength of $50 \%$ fly ash or slag based specimens even at early-age ( 3 days). Nano-silica contributes to improving the hardened properties of cement-based materials by multiple mechanisms, including accelerating the pozzolanic reactivity (Kong et al., 2012; Ghazy et al., 2016b), filling effect (Kong et $a l ., 2012$ ), and water absorption within the high surface area of nano-silica agglomerates, resulting in reduction of $w / b$ in the paste (Kong et al., 2012).

The nano-modified slag-based composites showed significantly higher compressive strength at early- and later-ages compared to the fly ash-based counterparts. For example, the compressive strengths of G-4.5 specimens at 3 and 28 days were $70 \%$ and $46 \%$, respectively, higher than that of F-4.5 specimens (Table 4). This difference at can be attributed to the relatively finer particles of slag $\left(492 \mathrm{~kg} / \mathrm{m}^{2}\right)$ compared to the fly ash particles $\left(292 \mathrm{~kg} / \mathrm{m}^{2}\right)$ which positively influenced the reactivity of slag with the coexistence of nano-silica. In addition, the chemical composition of slag had higher content of lime $(\mathrm{CaO})$ of about $43 \%$ which typifies slag with its faster hydraulic property within 28 days. Comparatively, Type F fly ash had low content of lime (about $11 \%$ ) and higher content of silica (55\%) imparting a pozzolanic reactivity over a longer period of time.

The effect of increasing the dosage of BFP was significant at reducing the compressive strength of fly ash- and slag-based composites. For example, at 28 days, Table 4 shows that the reduction in compressive strength for the fly ash-based composites F-4.5 and F-6.9 was $11 \%$ and $14 \%$, respectively relative to that of mixture F-2.5; correspondingly, the reduction for the slag-based composites G-4.5 and G-6.9 was $11 \%$ and $27 \%$, respectively relative to mixture G-2.5. Branston et al. (2016) reported a similar trend of compressive strength reduction with the increase of the BF minibars dosage $(0.3,1$ and $2 \%$ by volume) in ordinary concrete $(37 \mathrm{MPa})$. This can be attributed to the creation of additional interfacial transitional zones (ITZs) with higher dosages of BFP, which acted as weak links and stress concentrators in the matrix, thus reducing the compressive capacity of composites. However, the range of compressive strength for all mixtures at 28 days was 46 to $79 \mathrm{MPa}$, which highlights the adequacy of these binders to a suite of infrastructure applications (e.g. roads, bridges, tunnels, patch repair), which typically require a design compressive strength of 30 to $40 \mathrm{MPa}$ at 28 days (MacGregor, 1997). Generally, fibers/pellets are mainly added to mortar/concrete to enhance the flexural post- cracking, as discussed in the subsequent section. 


\section{Flexural Performance}

Table 4 lists the flexural and residual strengths as well as toughness for all mixtures at 28 days, based on the load-deflection $(P-\delta)$ curves shown in Figures $\mathbf{4}$ and 5.

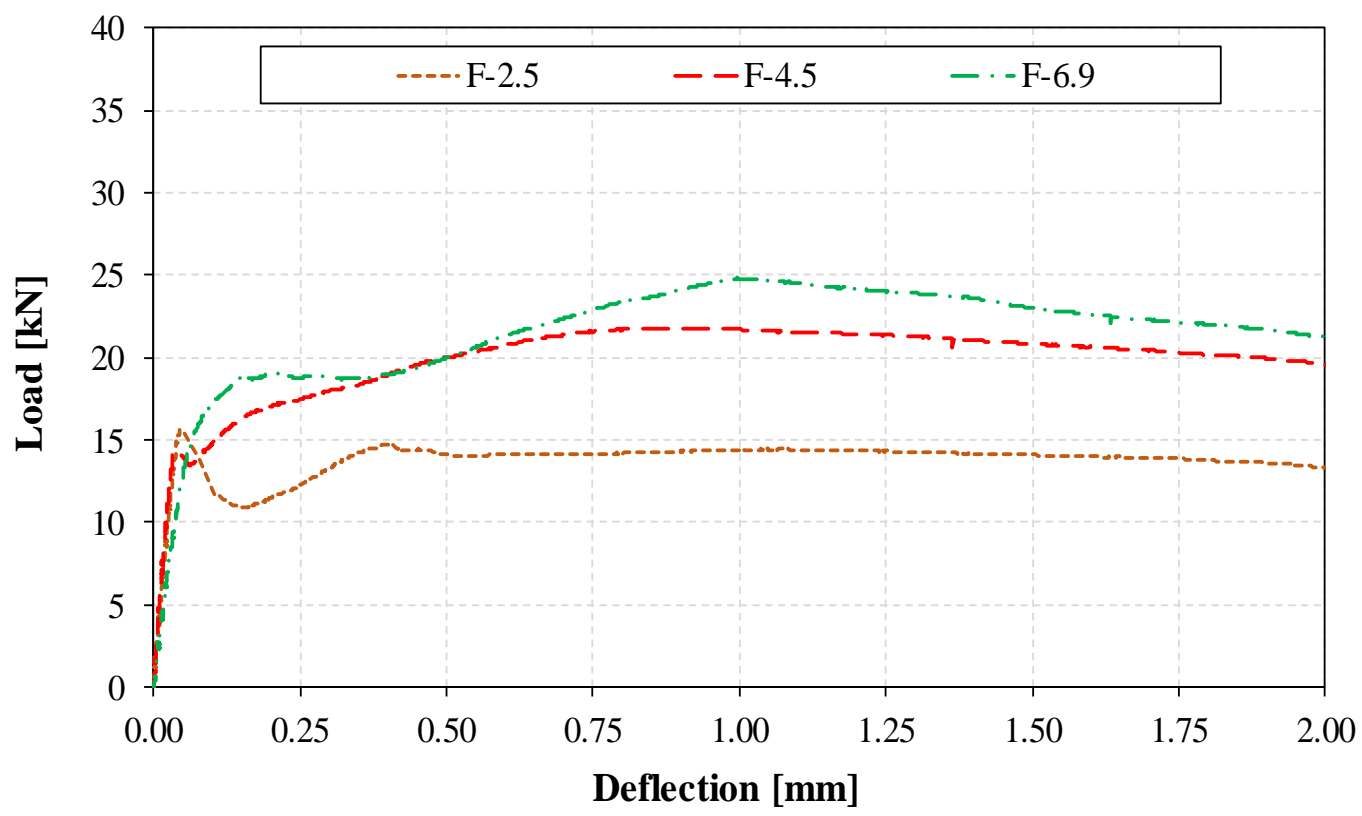

Figure 4- Load-deflection ( $P-\delta)$ curves for fly ash composites.

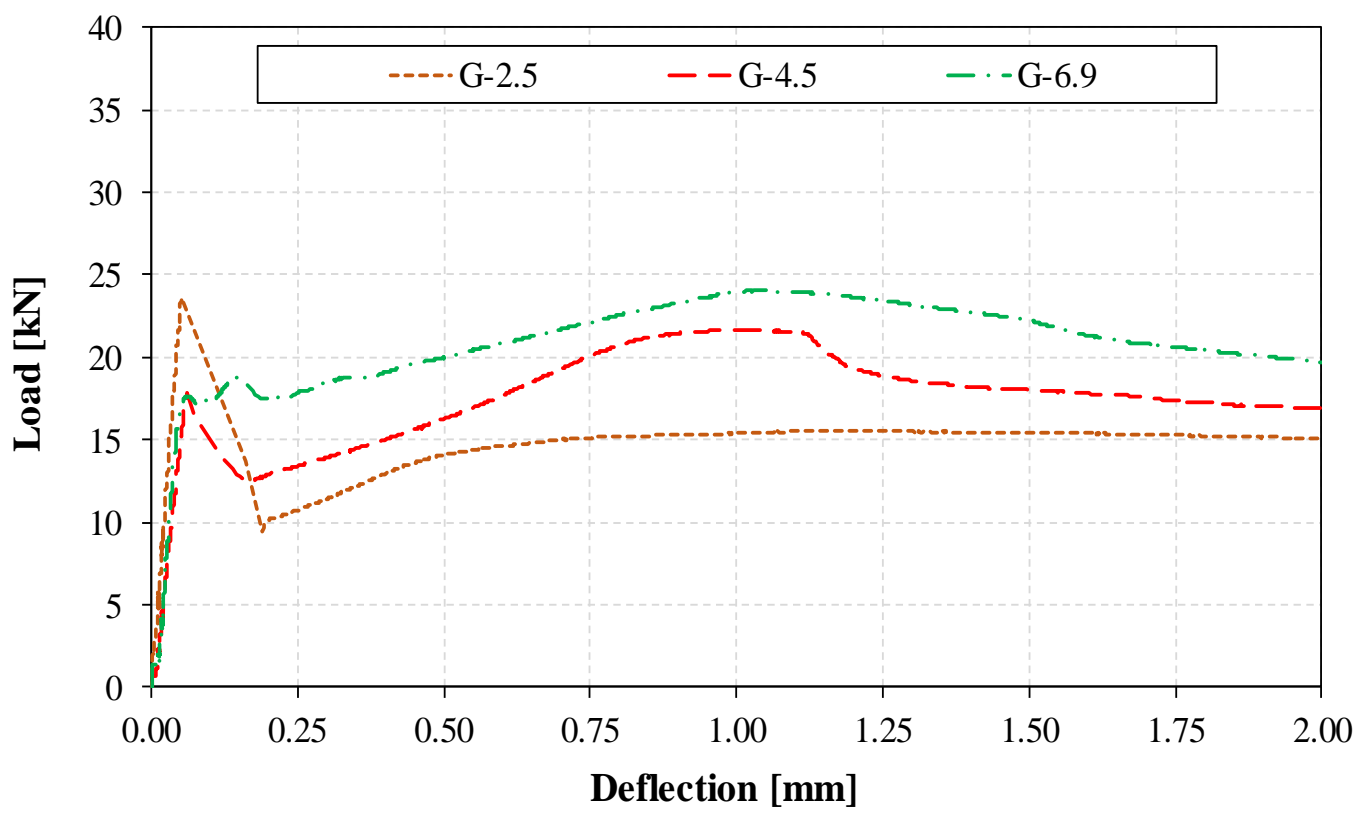

Figure 5- Load-deflection (P- $\delta)$ curves for the slag composites. 
It was observed that as the BFP dosage increased, the first-peak flexural strength decreased with different levels, depending to the type of binder. For instance, the reduction of the first-peak flexural strength for the fly ash-based composites F-4.5 and F-6.9 was $11 \%$ and $13 \%$, respectively relative to F-2.5, while the reduction for the slag-based composites G-4.5 and G-6.9 was $31 \%$ and $35 \%$, respectively relative to G2.5. Conforming to the compressive strength results, this can be attributed to the higher intensity of the ITZs created in the cementitious matrix with the incorporation of higher dosages of BFP. Initiation and propagation of micro-cracks may readily occur in these zones, thus reducing the flexural capacity (based on the first-peak crack) of the composites, which mainly depends on the cementitious matrix. However, the flexural strength of all composites was in the range of 4.5 to $7.3 \mathrm{MPa}$, which is appropriate for a range of infrastructure applications including roads, bridges, tunnels, and patch repair (MacGregor, 1997).

Representative P- $\delta$ curves for all the composite mixtures are shown in Figures 4 and 5. The mid-span deflection was measured by two LVDTs attached to the specimens. The specimens exhibited improved post-cracking behavior, especially for the BFP dosages $4.5 \%$ and $6.9 \%$. In General, the pellets had little effect on the behavior at the pre-cracking stage relative to the post-cracking one; this is because a comparable elastic behavior was obtained before the first cracking. After first cracking, a sudden drop in the bearing load was observed; however, the specimens were able to restrain the cracks as well as restoring the load-carrying capacity till reaching a second peak, but the residual load trend and level depended on the dosage of BFP. Composites with $2.5 \%$ BFP showed a post-cracking plateau. Comparatively, the mixtures with the higher BFP dosage, $4.5 \%$ and $6.9 \%$, exhibited a deflection-hardening process followed by a downward trend, resembling cementitious composites incorporating ductile fibers such as steel. For example, the average residual strengths of mixtures F-6.9 and G-6.9 were $33 \%$ and $24 \%$ higher relative to their first-crack flexural strength.

In addition, the post-cracking behavior of the mixtures can be generally assessed by the toughness (total area under the P- $\delta$ curve). The toughness of the developed composites increased with the BFP dosage (Table 4). In the fly ash group, mixtures F-4.5 and F-6.9 had a toughness of $36 \%$ and $45 \%$ higher than that of mixture F-2.5, which had a toughness of $27.4 \mathrm{~J}$. The toughness of mixtures G-4.5 and G-6.9 was 33\% and $45 \%$ higher than that of mixture G-2.5. The higher BFP dosages provided better chance for the pellets to exist at the failure planes and efficient restraint to propagation of cracks. It appears that abundant BFP in these locations arrested and bridged microcracks, resulting in improved toughness beyond the first cracking.

Besides, the toughness of the slag-based mixtures was slightly higher than that of their fly ash-based counterparts. The toughness of mixtures G-2.5, G-4.5 and G-6.9 were $10 \%, 7 \%$ and $10 \%$ higher than that of the corresponding fly ash mixtures. Testing specimens up to complete failure revealed that the distribution of BFP in the slagbased mixtures was more even relative to the fly ash composites, which showed some settlement/clustering towards the bottom of specimens (e.g. Figure 6). 

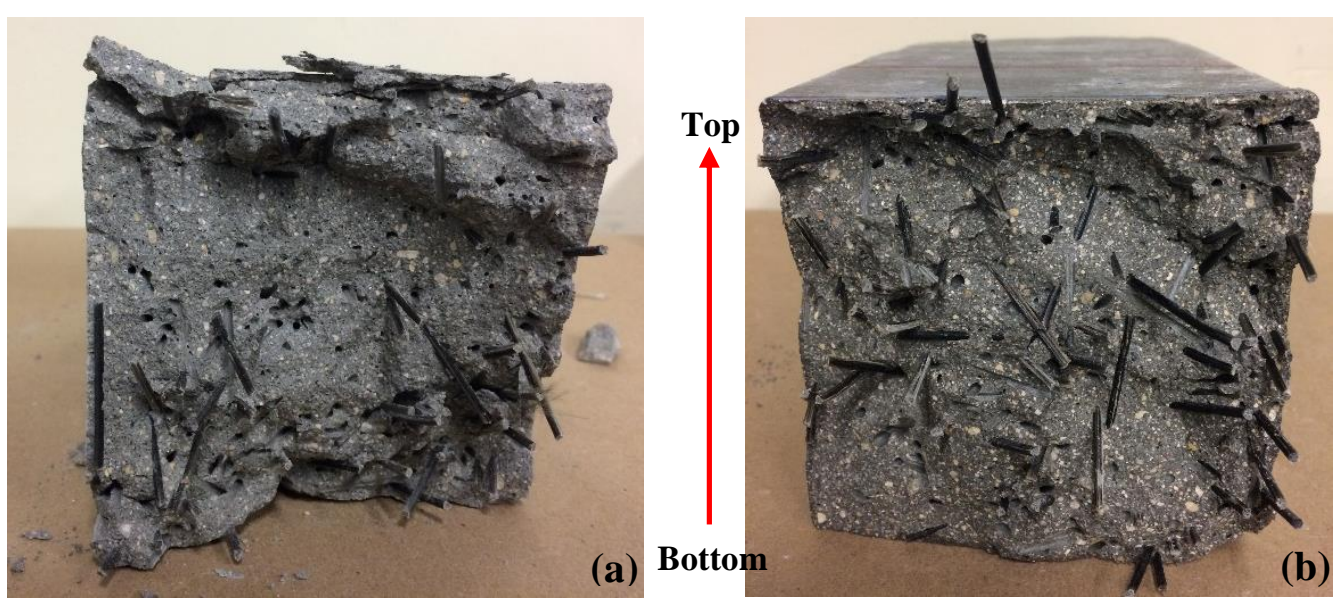

Figure 6- Distribution of BFP in the failure planes: (a) F-4.5, and (b) G-4.5.

It seems that the cohesive nature of the slag-based mixtures, considering the angular slag particles, had an interlocking effect on the pellets, which allowed its homogenous dispersion within the cross section during the plastic stage. In addition, the relatively faster reactivity of slag (latent hydraulic binder) to fly ash (slowly reactive pozzolan), as discussed in the compressive strength section, led to better bonding between the slag-based matrix and the pellets at 28 days, thus increasing the resistance to pellets pull out and toughness.

\section{CONCLUSIONS}

Based on the materials, designed composites and tests used in this research, the following concluding remarks can be made:

- The addition of 6\% nano-silica with 50\% fly ash or slag significantly improved the rate of hydration and pozzolanic reactions of the binders, which mitigated the retarding effect of high volume SCMs on the setting time and strength development.

- The compressive and flexural strengths of the composites decreased with the BFP dosage. The increase of BFP dosage created additional ITZs in the matrix, thus reducing the strength.

- BFP contributed to improving the flexural performance of the developed composites in terms of post cracking-behavior. In particular, composites comprising $4.5 \%$ and $6.9 \%$ BFP showed deflection-hardening behavior with significantly improved toughness and residual strength.

- All the composites developed herein had normal setting time, early-strength above $30 \mathrm{MPa}$ at 3-days and adequate compressive (47 to $79 \mathrm{MPa}$ ) and flexural (4.6 to $7.3 \mathrm{MPa}$ ) strengths at 28 days, with enhanced post-cracking behavior. Thus, these nano-modified composites may present a viable and sustainable option for a suite of infrastructure applications such as pavements and bridges. 


\section{ACKNOWLEDGEMENT}

The authors highly appreciate the financial support from Natural Sciences and Engineering Research Council of Canada (NSERC RGPIN/4024-2014). The IKO Construction Materials Testing Facility at the University of Manitoba in which these experiments were conducted has been instrumental to this research.

\section{REFERENCES}

ASTM C1609/C1609M. (2012). "Standard Test Method for Flexural Performance of Fiber-Reinforced Concrete (Using Beam With Third-Point Loading)." Annual book of ASTM standards. West Conshohocken, Pennsylvania, USA.

ASTM C230/C230M. (2014). "Standard specification for flow table for use in tests of hydraulic cement." Annual book of ASTM standards. West Conshohocken, Pennsylvania, USA.

ASTM C39/C39M. (2018). "Standard test method for compressive strength of cylindrical concrete specimens." Annual book of ASTM standards. West Conshohocken, Pennsylvania, USA.

ASTM C403/C403M. (2016). "Standard Test Method for Time of Setting of Concrete Mixtures by Penetration Resistance." Annual book of ASTM standards. West Conshohocken, Pennsylvania, USA .

ASTM C494/C494M. (2013). "Standard specification for chemical admixtures for concrete." Annual book of ASTM standards. West Conshohocken, Pennsylvania, USA.

Balaguru, P.N. and Shah, S.P. (1992). "Fiber-reinforced cement composites." Corporate Authors: McGraw-Hill Incorporated, New York, NY United States

Bentur, A. and Mindess, S. (2014). "Fibre Reinforced Cementitious Composites." Second Edition. London, UK: CRC Press.

Branston, J., Das, S., Kenno, S. Y., \& Taylor, C. (2016). "Mechanical behaviour of basalt fibre reinforced concrete." Construction and building materials, 124, 878886.

CAN/CSA-A3001. (2013). "Cementitious materials for use in concrete." Canadian Standards Association, Mississauga, ON, Canada.

Cheah, C. B., \& Ramli, M. (2014). "The fluid transport properties of HCWA-DSF hybrid supplementary binder mortar." Composites Part B: Engineering, 56, 681690.

Ghazy, A., Bassuoni, M. T., Maguire, E., \& O’Loan, M. (2016a). "Properties of fiberreinforced mortars incorporating nano-silica." Fibers, 4(1), 6, 16 p.

Ghazy, A., Bassuoni, M. T., \& Shalaby, A. (2016b). "Nano-modified fly ash concrete: A Repair Option for Concrete Pavements." ACI Materials Journal, 113(2), 231242.

Jones, W., Y. Farnam, P. Imbrock, J. Spiro, C. Villani, M. Golias, J. Olek, and W. J. Weiss. (2013). "An Overview of Joint Deterioration in Concrete Pavement: 
Mechanisms, Solution Properties, and Sealers." Purdue University, West Lafayette, Indiana. doi: 10.5703/1288284315339.

Kong, D., Du, X., Wei, S., Zhang, H., Yang, Y., \& Shah, S. P. (2012). "Influence of nano-silica agglomeration on microstructure and properties of the hardened cement-based materials." Construction and Building Materials, 37, 707-715.

Lee, J. J., Song, J., \& Kim, H. (2014). "Chemical stability of basalt fiber in alkaline solution." Fibers and Polymers, 15(11), 2329-2334.

Li, V. C. (2010). "Sustainable pavement overlays using engineered cementitious composites." International Journal of Pavement Research and Technology, 3(5), 241-250.

Li, M.; Ranade, R.; Kan, L.; Li, Victor C. (2010). "On improving the infrastructure service life using ECC to mitigate rebar corrosion." Proc., 2nd Int'l Symp. on Service Life Design for Infrastructure, Delft, The Netherlands, RILEM PRO 70, Edited by K. van Breugel, G. Ye, and Y. Yuan, pp. 773-782.

Li, V.C. (2003). "Durable overlay systems with engineered cementitious composites (ECC)." International Journal for Restoration of Buildings and Monuments. 9 (2), $20 \mathrm{p}$.

MacGregor, J. G., Wight, J. K., Teng, S., and Irawan, P. (1997). "Reinforced concrete: Mechanics and design." Third edition" Upper Saddle River, NJ: Prentice Hall.

Mahmoud, K., Ghazy, A., Bassuoni, M.T. and El-Salakawy, E. (2017). "Properties of Nano-modified Fiber-Reinforced Cementitious Composites." Journal of Materials in Civil Engineering, 29(10), p.04017173.

Mehta, P. K., and Monteiro, P. J. M. (2014). "Concrete." McGraw Hill Education, USA.

Neville, A. M. (2011). "Properties of concrete." Prentice Hall, London, UK.

Ondova, M.; Stevulova, N.; and Meciarova, L. (2013). "The Potential of Higher Share of Fly Ash Cement Replacement in the Concrete Pavement." Procedia Engineering, 65, pp. 45-50.

Ramezanianpour, A. A. (2014). "Cement Replacement Materials Properties, Durability, Sustainability." Springer-Verlag Berlin Heidelberg.

Said, A.M., Zeidan, M.S., Bassuoni, M.T. and Tian, Y. (2012). "Properties of concrete incorporating nano-silica." Construction and Building Materials, 36, 838-844.

Zhang, M., Islam, J., and Peethamparan, S. (2012). "Use of nano-silica to increase early strength and reduce setting time of concretes with high volumes of slag." Cement and Concrete Composites, 34(5), 650-662.

Zhu, Y., Yang, Y. and Yao, Y. (2012). "Use of slag to improve mechanical properties of engineered cementitious composites (ECCs) with high volumes of fly ash." Construction and building materials, 36, 1076-1081. 